\title{
Understanding plagiarism \\ The role of librarians at the University of Tennessee in assisting students to practice fair use of information
}

$l^{n}$ this age of information technology, the

Internet has brought tremendous changes to the academic and research world. The Internet has had a dramatic effect on the way information is created, organized, accessed, and disseminated. Information can now be accessed easily through databases, the Internet, electronic lists, and various other formats.

In the academic world, though academic dishonesty is not a new phenomenon, it is widely acknowledged that access to online information has made it easier and more tempting to copy or quote another person's original work without attribution.

Research indicates that culture and language barriers play a role, as well. In light of this, many "academic institutions have responded to this threat by developing integrity policies that typically use punitive methods to discourage cheating, plagiarism, and other forms of misconduct," ${ }^{1}$ but plagiarism is still widespread at most institutions.

How can these communities acquire proper writing and research skills to enable them to avoid plagiarism? What can librarians do to encourage ethical use of information within the communities they serve? Is information literacy the answer, or is it the responsibility of each individual to respect intellectual property?

This article will discuss what plagiarism is and illustrate ways librarians at the University of Tennessee (UT) have promoted the ethical use of information in the university community. The international/intercultural perspective on plagiarism will also be discussed in order to highlight the attributes plagiarism.

\section{Defining plagiarism}

Plagiarism comes from the Latin word plagiarius, ${ }^{2}$ which means abducting or kidnapping. This implies that it is an act of taking the writings or creative work of another person and passing them off as one's own. Plagiarism involves "submitting work created by a professional service (either in whole or in part), and used without attribution." 3

Individuals can also download or order papers from the Web through commercial papermills and copy and paste either text or graphics from electronic databases without giving proper documentation. In addition, plagiarism can also involve "patchworking writing passages that are not copied exactly, but that have nevertheless been borrowed from another source, with some changes." ${ }^{4}$

\section{Why talk about plagiarism?}

Plagiarism is dishonesty or cheating that can result in failure in a course or dismissal from the university. "It devalues other people's original work and takes an unfair advantage over other people's efforts."

In the academic world, research is about producing original work and further developing good writing and research skills. It is, therefore, imperative for students to be aware of what plagiarism entails.

Maud Mundava is social sciences librarian at the University of Tennessee, e-mail: mmundava@utk.edu, and Jayati Chaudhuri is science reference librarian at the University of Northern Colorado Libraries, e-mail: jayati.chaudhuri@unco.edu

๑) 2007 Maud Mundava and Jayati Chaudhuri 


\section{Concepts of plagiarism in an English- speaking world}

There are different notions about plagiarism around the world that can confuse students. The concept of ownership of ideas and written expressions exists in the English-speaking countries. ${ }^{6}$ Authors have the right to own the phrases or ideas written exclusively by the author. It is unacceptable to use those words without giving proper credit to the author.

\section{Concepts of plagiarism in other countries of the world}

As stated above, the different perception of plagiarism can be confusing to some students, especially international students. In other societies, information is shared and is believed to be owned by the whole society. ${ }^{7}$ It is therefore, acceptable to use others' words without giving credit. In some societies, written documentation did not fully develop until the early 1900s. In the past people relied on oral tradition and folk stories. As result, ideas and concepts were not owned by an individual, but rather by the society. Hence, citing was not necessary. With this in mind, plagiarism can then be confusing for someone who is coming from a society where plagiarism is not taken seriously as it is in the Western culture.

The University of Minnesota studies show that " $85 \%$ of all scholastic dishonesty cases related to plagiarism involved nonnative speakers of English. While non-native speakers are no less honest than their native-speaker peers, this finding indicates that it may be easier to spot plagiarism in a non-native speaker's writing (e.g., through sharp shifts in tone, word choice, or grammar usage)." 8

In cases such as this, it is vital for students to be aware of the correct use of citation manuals and understand what plagiarism entails. Software tools for publishing and managing bibliographies such as Endnote, Procite, and Reference Manager can "save countless hours of typing and interpreting style requirements . . . by generating a perfectly formatted document" for the writer.?

\section{Influences that shape academic dishonesty}

Research illustrates that there is no agreement as to why plagiarism is prevalent among college students. There are many possible factors that contribute to plagiarism:

- ignorance about what plagiarism is;

- failure to understand that collaborative writing, downloading images from the Internet, or incorrect paraphrasing without proper citation is wrong;

- the quest for good grades at any cost;

- the pressure of work, laziness, or the recognition that everyone is doing it (journalists, historians, politicians etc); and

- frustration with the writing process caused by variation in citation style manuals causes.

Some educators state that students have always plagiarized, but the arrival of the Internet has made it easy to copy and paste information from the Web. The proliferation of free and paid paper mills on the Internet is another factor enticing students to plagiarize. Some of the popular paper mills can be found at www.bignerds.com and AntiEssays. com. An example of a paid-for paper mill is www.academictermpapers.com. ${ }^{10}$

In view of the above, it is clear that librarians can make a difference in raising awareness about these issues. Librarians at UT have developed programs to reduce plagiarism incidences in the university community.

\section{UT librarians in action}

Plagiarism is not a new phenomenon, but the extent to which it is occurring makes it an issue of concern in most learning and educational institutions. The UT Libraries has been proactive in finding ways to deter plagiarism among its clientele and the university community at large. Even though there is no statistical information to illustrate the extent to which plagiarism is a problem at UT, the 
librarians are committed to spreading the word on ethical use of information.

\section{Workshops/instruction}

Librarians have long been strong advocates for information literacy and lifelong learning among their constituencies, but plagiarism remains an issue of concern. To assist in curbing incidences of plagiarism, the UT librarians initiated a plagiarism workshop series in fall 2003. These workshops were initially organized with undergraduate students in mind, but later adapted to the needs of faculty and graduate assistants who asked for help to encourage their students to practice fair use of information.

In addition to the campuswide workshop series, the library has collaborated with the International House to organize workshops focused on international students. In these workshops, students had an opportunity to discuss how plagiarism is regarded in their different cultures and to consider the relationship of language as a barrier to effective writing and learning skills. These specialized workshops have not been well attended, so librarians are seeking other ways to engage international students in these discussions.

To complement the workshops, a guide on understanding plagiarism was created to assist students, faculty, and graduate assistants in respecting the writing efforts of others. An information literacy tool kit, which was designed by the reference team, is another initiative that can enable students and faculty to promote fair use of information. The cooperation of the teaching faculty, the Writing Center, and support from the campus administration, the Office of Student Judicial Affairs, and student organizations is critical to changing attitudes among students. Without their support, librarians' efforts will not materialize.

\section{Enabling success}

At any academic institution librarians, faculty, and students can collaborate to promote the ethical use of information.

- Librarians. It is vital that librarians work closely with faculty and other groups discussed above to maintain an atmosphere of intellectual integrity and academic honesty. Librarians should continue making users aware of what plagiarism entails. Involvement of the subject librarian has been proven to be beneficial. They should persistently disseminate appropriate information about good writing and research skills. Emphasis on illustrating the value of library resources and on developing good research skills vis á vis copying and pasting Internet resources is essential. In addition, effective use of writing centers could be useful especially for second-language speakers.

Faculty. Faculty can create assignments that help students adhere to the honor statement. Teaching faculty should remind students that plagiarism is a "crime" and it needs to be taken seriously. ${ }^{11}$ Faculty can also design unique assignments that encourage critical thinking and analysis. Most research confirms that some teaching faculty are reluctant to act on plagiarism perpetrators, hence, the increase in plagiarism incidences in higher education. Faculty should collaborate with the library to organize sessions that enhance students' writing and research skills, and the use of style manuals and citation software, such as EndNote.

Students. It is essential that students understand what plagiarism entails and how they can avoid it. Through attending library instruction sessions, they empower themselves with better research and writing skills. Given enough time for each assignment, copying and pasting from Internet sources or collaborating on assignments without the instructor's approval will be less tempting. It is important for students to develop appropriate skills on how to paraphrase, summarize, and use quotations. Use of more authentic and reliable resources from the libraries such as full text from research databases and other secondary and primary sources is encouraged.

\section{Marketing strategies}

Initially the Daily Beacon, UT's student newspaper, was instrumental in the suc- 
cess of one of the workshops that was well attended, especially by faculty. ${ }^{12}$ Subject librarians also help to spread the word to their departments and students. Bookmarks that were created are sometimes distributed during the plagiarism workshop, at the International House, and at other appropriate campus events.

The university festivals, such as the Annual International Students' Festival, also presents an opportunity to raise awareness on "how to avoid plagiarism" to the university community. During this festival in 2005, librarians created and distributed plagiarism bookmarks. Even though the idea of highlighting plagiarism is still new, we plan to do it on a wider scale throughout the campus. The Life of the Mind, a program for freshman to read and discuss a book before classes begin, is another venue through which to educate the students about plagiarism.

Librarians should continue placing emphasis on information literacy skills and providing avenues to encourage the use of the resources in libraries. Attending conferences and joining appropriate electronic lists present opportunities to discuss the issues surrounding plagiarism. Further research on the topic is also important. Organizing a campus-wide discussion forum that involves the students, the Writing Center, the office of Judicial Affairs, teaching assistants, librarians, and faculty could also be useful.

\section{Conclusion}

Librarians have a key role in helping the academic community avoid plagiarism. A combined effort among the library, the Writing Center, teaching faculty, student government and services, and the administration will build a community that respects intellectual property and academic integrity. As stated in an article in Library Trends, "Preventing plagiarism before it happens is better that detecting it after the event." 13

\section{Notes}

1. Rebecca Mercuri, "In Search of Academic Integrity," Communications of the $A C M$ 41, no. 5 (1998): 136, delivery.acm. org/10.1145/280000/274964/p136mercuri. pdf?key $1=274964 \&$ key $2=7643094611 \&$ coll $=$ portal $\& \mathrm{dl}=\mathrm{ACM} \& \mathrm{CFD}=5804121 \& \mathrm{CFTOKEN}$ =69358748 (accessed November 30 2006).

2. Brian Hansen, "Combating Plagiarism," The CQ Researcher Online 13, no. 32 (September 19, 2003): 773-796, library.cqpress. com/cqresearcher/cqresrre2003091900 (accessed May 11, 2005).

3. Office of the Dean of Students, "Hilltopics: Student Handbook 2003-2004," The University of Tennessee, Office of the Dean of Students, (2004): 11-40, web.utk. edu/ homepage/hilltopics/Hilltopics2004. pdf.7. Diane Scarponi, "University President Plagiarized," Miami Herald.com, March 2004, www.miami.com/mld/miamiherald /news/nation/8211339.htm. (accessed May 17, 2005).

4. Rebecca Moore Howard, "Plagiarisms, Authorships, and the Academic Death Penalty," College English 57, no. 7 (November 1995): 799.

5. UC Davis Student Judicial Affairs, "Avoiding Plagiarism," UC Davis Student Judicial Affairs, sja.ucdavis.edu/avoid.htm (accessed May 13 2005).

6. Sharon Myers, "Questioning Author(ity): ESL/EFL, Science, and Teaching about Plagiarism," TESL-EJ 3, no.2 (1998): 1-15, www. writing.berkeley.edu/TESL-EJ/ej10/a2.html (accessed June 13 2005).

7. Ibid.

8. Sheryl Holt, "Plagiarism: Culturally Cultural Groups”, n.d. swc.umn.edu /workshop_docs/Plagiarism.doc. (accessed January 26 2004).

9. Procite, www.procite.com/pcabout.asp.

10. Steve Gardiner, "Cybercheating: A New Twist on an Old Problem," Phi Delta Kappa, 83, no. 2 (2001): 172-74, www.epnet.com/.

11. CS140 Plagiarism Policy, www.cs.utk.edu/ cs $140 /$ spring 2005 /plagiarism.html.

12. See dailybeacon.utk.edu /showarticleold.php?id=16000.

13. Nicole J. Auer and Ellen M. Krupar, "Mouse click plagiarism," Library Trends 49, no. 3 (2001): 415-32. 